\title{
CORRESPONDENCE
}

\section{Absence of risk of colorectal cancer among workers at a UK polypropylene production plant}

Editor-Concern about the possibility of an association between colorectal cancer and polypropylene was raised by a report of a 5.6-fold increase in incidence of colorectal cancer in a small cohort of polypropylene production workers in the United States.

This letter describes the results of a study on the incidence and mortality of cancer in 384 workers employed at two polypropylene production plants at Carrington, Cheshire. The first plant opened in March 1972 and the second plant opened the next year. The cohort consisted of all workers employed at either plant for at least one year and the follow up period extended until June 1992. Information on vital status and cancer registration was obtained from the United Kingdom National Health Service Central Register. England and Wales rates of mortality and incidence of cancer were used to derive expected numbers of deaths and cancer cases

Twenty eight deaths occurred during the study period of which 11 had an underlying cause of a malignant neoplasm. Notifications were received of 14 cancer registrations. Only the results for mortality and incidence of colorectal cancer are presented here. A single case of colorectal cancer has been reported $(2 \cdot 28$ expected cases) and there have been no deaths due to colorectal cancer ( 1.36 expected deaths).

The earlier report of an excess of colorectal cancer was surprising as high molecular weight substances such as polypropylene are considered to be chemically inert with little or no physiological or toxicological effects and the monomer, propylene, showed no signs of carcinogenic activity in inhalation tests in rats and mice. ${ }^{2}$ Other studies of the same workforce, ${ }^{34}$ and evaluation of the additives and process agents present in the polypropylene manufacturing process, have not provided further aetiological leads. A study of workers employed in a pilot plant that produced polypropylene owned by the same company, showed no increased risk of colorectal cancer ${ }^{5}$ and a recent update of the study of the polypropylene production workers from the United States that initiated the concern, has indicated no continuation of risk after the occurrence of the original cluster of cases.

The absence of risk in the study described in this letter is consistent with other recent studies of polypropylene production workers in Australia ${ }^{7}$ and Germany, ${ }^{8}$ and further strengthens the argument against a causal relation between polypropylene and colorectal cancer. It should be noted, however, that the study has low power and the longest period of follow up is only 20 years.

$$
\begin{array}{r}
\text { J BOUSKILL } \\
\text { Shell Chemicals UK Limited, } \\
\text { Carrington Works, } \\
\text { Urmston, } \\
\text { Manchester M314Af }
\end{array}
$$

1 Acquavella JF, Douglass TS, Philips SC Evaluation of excess colorectal cancer incidence among workers in the manufacture of polypropylene. $f$ Occup Med 1988;30: $438-42$.

2 Ciliberti A, Maltoni C, Perino G. Long-term carcinogenicity bioassays on propylene administered by inhalation to SpragueDawley rats and Swiss mice. Ann NY Acad Sci 1988;534:235-45.

3 Acquavella JF, Douglass TS, Vernon $S$, Hughes JI, Thar WE. Assessment of colworkers involved in polypropylene manufacture. $\mathcal{F}$ Occup Med 1989;31:785-91.

Yarborough CM, Lynch J. An adenomatous polyp case-control study to assess occupational risk factors following a workplace col-
orectal cancer cluster. Am $\mathcal{f}$ Epidemiol 1991;133:357-67.

5 Acquavella JF, Owen CV. Assessment of colorectal cancer incidence among polypropy1990;32:127-30.

6 Lewis RJ, Schnatter AR, Lerman SE. Colorectal cancer incidence among polypropylene manufacturing workers: an polypropylene manufacturing work

7 Bisby JA, Adams G, Roberts M, Botham I Baade A. Health watch, 9th annual report. Melbourne: The Australian Institute of Petroleum Health Surveillance Program. Department of Public Health and Community Medicine. University of Melbourne, 1992

8 Kaleja R, Horbach L, Amsel J. Polypropylene production workers and colorectal cancer in Germany: a brief report. Occup Environ Med 1994;51:784-5.

\section{Isotretinoin induced rubber glove} dermatitis

Editor-A 25 year old final year medical student presented to the occupational health unit during her obstetric attachment with a punctate, scaly, erythematous rash orectal cancer screening outcomes among

4 Acquavella JF, Owen CV, Bird MG, polyp case-control study to assess occupa-
tional risk factors following a workplace collene pilot plant employees. $\mathcal{F}$ Occup Med

on the dorsum of both hands (figure) There was a clear association between the initial onset of the rash, exacerbations, and wearing of surgical gloves for obstetric delivery. She was advised to avoid wearing gloves and the symptoms resolved within a week. Further glove wearing did not reproduce symptoms.

She had worn a wide variety of gloves throughout her clinical training, including those associated with the rash. She had not had problems previously. She had a family history of atopy but had never experienced symptoms herself.

Four months previously she had started a course of isotretinoin (Roaccutane-Roche) for facial acne. The course finished one week after the glove rash resolved. She was on no other medication. Patch tests were carried out four weeks after the rash had resolved. The European standard battery of patch test allergens, as well as samples of all the gloves worn proved negative.

Isotretinoin induced susceptibility to the irritant effect of rubber gloves is the most likely explanation for this shortlived episode of dermatitis. Redness and dryness of the skin are well recognised side effects of isotretinoin; however this apparent ability to precipitate irritant contact dermatitis is less well known. There is only one other case of isotretinoin; associated contact dermatitis in the scientific literature and this followed the use of epilation wax for facial hair.

Irritant and allergic contact dermatitis to gloves is a serious condition for health care workers with clinical contact. Infection control procedures dictate that sufferers must be removed from patient care. This has cost implications and may also result in psychological morbidity. In some cases permanent redeployment is necessary and in extreme cases retirement on grounds of ill health. Most health care workers with clinical contact are young women. This group is one of

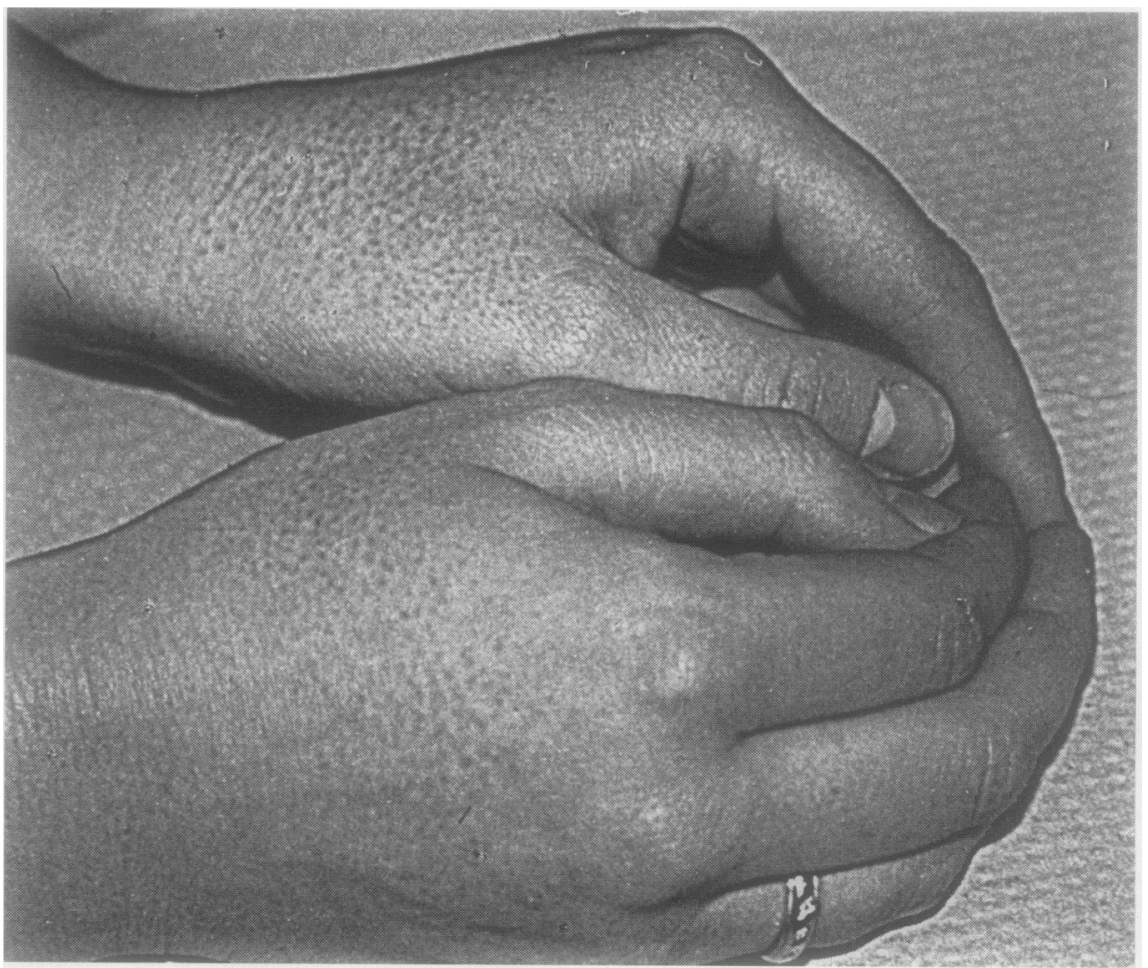

Dorsum of hands showing a fine papular erythema. 
those most likely to be treated with isotretinoin. It is important that occupational physicians are aware of this possible side effect so that it can be discussed with the patient when considering treatment of acne, and considered when managing a case of possible glove allergy S WRIGHT

Royal Free Hospital and School of Medicine

London

1 Egido Romo $M$. Isotretinoin and wax epilation. Br f Dermatol 1991;124:393.

\section{NOTICES}

International course in Modern Epidemiology, at Luteren, The Netherlands, 15-18 May 1995

This is an advanced course about principles of epidemiological research.

Lecturer: KJ Rothman. Among others, the topics will be: case-control research principles, interaction in a etiology, statistics $v$ epidemiological analyses.

Enrolment is open to researchers with a basic knowledge of epidemiology and biostatistics and at least some working experience.

Closing date for enrolment is January 13, 1995.

For additional information please contact: Mrs Astrid van Alst, Course secretary, Department of Epidemiology, University of Nijmegen, PO Box 9101, 6500 HB Nijmegen, The Netherlands. Tel +31-80-619132; Fax: +31-80-613505.

\section{NIVA NORDISK Courses and Symposia 1995}

Advanced course for leaders of interdisciplinary research projects. 6-10 February 1995 Vilvorde Course Centre, Charlottenlund, Denmark.

Individual susceptibility to occupational toxicity-II. 13-17 February 1995 Highland Hotel, Geilo, Norway.

Physiological responses to physical and mental work-II. 27-31 March 1995 Soria Moria Course Center, Oslo, Norway.

Current trends in research on work related musculoskeletal disorders-III. 24-28 Apri 1995 Schaeffergaarden, Gentofte, Denmark.

Participative approaches to workplace design-II. 24-28 April 1995 Finland.

Ethical issues in occupational health research. 7-10 May 1995 Valamo Monastery, Hein, vesi, Finland.

Occupational respiratory hypersensitivityV. 4-8 June 1995 The Imatra State Hotel, Imatra, Finland.

International quality standards in occupational measurements-II. 5-8 June 1995 Rungsted gaard, Rungsted kyst, Denmark. Introduction to occupational epidemio-
logy-III. 14-25 August 1995 Gentofte, (Copenhagen) Denmark.

Epidemiologic study design-IX. 14-25 August 1995 Hanasaaari Cultural Centre, Espoo (Helsinki), Finland.

Occupational safety and health among seamen, fishermen, and employees in the fish industry. 5-8 September 1995 Nordens Hus, Faroe Islands.

Methods and strategies for estimation and measurement of air pollutants in work places. 16-20 October 1995 Sweden.

Safety research-II. 6-10 November 1995 Hotel Saga, Reykjavik, Iceland.

Risk assessment and risk management for the working environment. 13-17 November 1995 Hotel Marina, Vedbaek, Denmark.

Productivity impact of occupational health and safety. 6, 13, 20, and 27 November $1995 \mathrm{NIOH}$ at Helsinki, Solna, Oslo, and Copenhagen.

Enquiries to: NIVA, Topeliuksenk. 41 a A, FIN-00250 Helsinki, Finland. Tel +358-0-47471; Fax: + 358-0-4747 497 .

Eleventh International Symposium on Epidemiology in Occupational Health. Noordwijkerhout, within easy reach of Amsterdam, The Netherlands. 5-8 September 1995.

The conference will be organised by the Departments of Epidemiology and Public Health and Air Quality of the Agricultural University Wageningen, The Netherlands, and Department of Public Health of Erasmus University Rotterdam, The Netherlands, on behalf of the Scientific Committee on Occupational Epidemiology, of the International Committee on Occupational Health ( $\mathrm{ICOH}$ ).

This Symposium will offer an excellent international platform to exchange knowledge on occupational epidemiology. It brings active research workers in occupational epidemiology together who review the state of the art concerning major and current issues in the field of occupational health; methodology, findings, and applications of their work will be discussed.

The ICOH launched in 1980 a successful tradition of providing a world wide forum to foster exchange among researchers.

The programme will include plenary and parallel sessions with invited and submitted papers related to the following themes:

- Methods in occupational epidemiology

- Occupational surveillance methods, evaluation, and ethical aspects

- Occupational diseases

- Occupational injuries

- Occupational cancer

- Neurological effects

- Respiratory diseases

- Musculoskeletal disorders

- Reproductive and developmental effects

- Work related stress

- Exposure assessment in occupational epidemiology

- Biomarkers

- Communicable diseases at work

- Occupational epidemiology.

For any inquiries or assistance, please contact the conference secretariat: $M$ Susan Peelen Msc, Department of Epidemiology and Public Health, PO Box 238, 6700 AE Wageningen, The Netherlands. Tel: + 318370 84124; Fax:
+ 318370 82782; e-mail susan.peelen@? medew.hegl.wau.nl

Faculty of Occupational Medicine; Fitness for Work. Launch of the second edition. At the Royal College of Physicians, Regent's Park, London NW1, on Thursday, 9 February 1995.

The launch of the second edition of this invaluable reference book, which has been completely rewritten, will take place at an all day conference on the subject.

The conference will be opened by $\mathrm{Sir}$ Bob Reid, Chairman of British Rail and London Electricity, and some of the contributors and other distinguished medical specialists on topics concerned with the relations between work and health will take part. As demand for places is expected to be heavy and numbers will be limited, you are advised to reserve your place early.

The conference will cover microinvasive surgery, drug abuse in the workplace, women at work, legal issues concerned in fitness for work, heart disease and driving, working on dialysis, new concepts in repair of the CNs, and a medfical view from the cockpit by a doctor who combines two professions, flying and medicine.

Contributors will include $\mathrm{Mr}$ James Wellwood, Professor Nicola Cherry, Mrs Gillian Howard, Dr Michael Petch, Dr Derek Manning, Dr Gerald Smith, Dr Laila Kapadia, Dr Tim Carter, Dr Peter Baxter, Dr Charles Veys, and Professor Malcolm Harrington.

The price of $£ 70$ includes attendance at the conference, lunch, coffee, tea and a complimentary copy of the second edition of Fitness for Work (normal retail price £18.50).

For further details please contact the Faculty of Occupational Medicine. Telephone: 0714873414 or fax: 0719352259. 